\title{
Investigation of the change of lockdowns applied due to COVID-19 pandemic on musculoskeletal discomfort
}

\author{
Halil Şengül1 ${ }^{1}$ \\ Arzu Bulut ${ }^{2}$ \\ Musab Abdullah Adalan ${ }^{3}$
}

\begin{abstract}
Objectives: COVID-19 pandemic has affected public health to a large extent. The rapid contamination of the disease has necessitated social distance and lockdown. Musculoskeletal discomforts are the most common complaints among routine medical complaints. Restraints caused by the pandemic and psycho-social effects have caused such complaints increase. In the present study, the aim is to determine whether there is a difference between the Musculoskeletal System Discomforts of the people before and during the COVID-19 pandemic and to reveal the factors affecting such a difference.

Material and Method: This study was carried out in descriptive design. In the study, the study group consisted 1138 people living at different cities of Turkey who accepted to participate in the study. As the data collection tool, the personal information form prepared by the researcher and the "Cornell Musculoskeletal Discomfort Questionnaire (T-CMDQ)", which was developed by Cornell and translated into Turkish by Erdinç et al. who also tested the validity and adaptation of the questionnaire, were used in the study. The test method conducted in computer environment was used as the data collection method. In the study, decision of the ethics committee was taken for the non-interventional practices (Dated 2020 with no. 06). Paired Sample t-Test statistics was used for data comparison in the study. Significance level was accepted as $\mathrm{p}<0.001$. In the study, Cronbach alpha value of the total score of Musculoskeletal Discomfort Questionnaire was found as 0.92 .

Results: It was determined that there was a statistically significant difference between the total mean scores of the participants before COVID-19 and during COVID-19 ( $p<0.001$ ). There was a statistically significant difference between the total mean scores of the participants regarding the pain level before COVID-19 and during COVID-19 ( $\mathrm{p}<0.001$ ).

Conclusion: During COVID-19, it is determined that there is a decrease in the frequency of feeling pain, aches, and discomfort in body regions, but an increase in the severity of the emergent discomforts.

Key words: Pandemic; Covid-19; lockdown; musculoskeletal system discomforts.

\footnotetext{
${ }^{1}$ Asst. Prof. Dr., Sabahattin Zaim University, Faculty of Health Sciences, Health Management Department, halil.sengul@izu.edu.tr (iD) Orcid ID: 0000-0001-5745-0369

2Ph.D. Candidate, Uskudar University, Faculty of Health Sciences, Health Management Department, arzublt80@gmail.com (iD) Orcid ID: 0000-0001-7362-5667

${ }^{3}$ M.Sc., Sabahattin Zaim University, Faculty of Health Sciences, Health Management Department, musabadalan@gmail.com (iD) Orcid ID: 0000-0002-8359-6158
} 

pandemic on musculoskeletal discomfort. Journal of Human Sciences, 17(4), 974-985. doi:10.14687/jhs.v17i4.6060

\section{Introduction}

The etiology of musculoskeletal discomforts is still not exactly understood however, there is a consensus that such discomforts are multifactorial in the nature (1). It is reported that physical exposures at work and the psychosocial risk factors have strong relationships with the musculoskeletal complaints related to neck, shoulder, forearm, and hands. Increasing computer use, static posture, and continuously repeating hand movements constitute an increased risk for musculoskeletal diseases (2).

In recent years, people do not only use computers at work or school, but also use cell phones, laptops, or tablet computers for communication and entertainment. Physical inactivity, being at the same posture for a long time, desk work, time elapsed with electronic devices such as mobile phones or tablets affect the comfort of the musculoskeletal system of people. Previous research has shown that using computers for more than four hours a day may contribute to the increase in the risk of musculoskeletal diseases $(2,3)$. Such discomforts include neck pain, shoulder rigidity, forearm tenosynovitis, carpal tunnel syndrome, and de Quervain syndrome (4). There are many studies on the negative effects of physical inactivity and being at the same posture, on the musculoskeletal system. Static and continuous sitting in front of the computer, unsettling postures of the shoulders, permanent non-neutral positions of the upper extremities including the upper back and neck, take place among numerous risk factors related to the musculoskeletal system. Studies conducted in the countries of European Union have shown that workplace-related musculoskeletal discomforts are more than all the other health problems and they constitute about half of work-related health problems. About one fourth of the European workers report that they experience pain in their upper extremities, shoulders, and neck (5).

In the studies conducted, the said problem related to the use of computers in the offices was related to the posterior segments, upper extremity, and neck (6, 7). According to a study conducted in Canada, three of every five office workers are dependent on computers while doing their jobs, and the annual rate of musculoskeletal discomforts is essentially affected by the abovementioned risk factors. Thus, it can be specified that the arrangements made as a result of ergonomic evaluations and the trainings to be given reduce these risk factors proactively (8). Improving the sitting standards or giving active breaks prevents the occurrence of the situations causing musculoskeletal discomforts. However, due to the COVID19 pandemic, the increase in working at home and failure to pay attention to the sitting standards in the home environment is an obstacle for taking the advantage of this opportunity.

COVID19 pandemic has forced people to stay and work at home. Turkey, especially in the context of pandemic Covid19 curfew restrictions applied to those living in metropolitan areas, people are forced to stay at home and work and reduce the mobility of people in this situation. This lockdown has also extended the time elapsed in front of the computers, mobile phones, and similar electronic devices. As the lockdown was applied to the general population only on weekends, it was declared for adolescents and children under 20 and people over 65 on all the days of the week. Due to the restraints applied for COVID 19 pandemic, a certain risk is posed for musculoskeletal discomforts (MSD). COVID19 has also caused anxiety and psycho-social discomforts in the population. Psycho-social discomfort is an important factor for the emergence of MSD (9).

There are various scales used to determine the musculoskeletal system discomforts. Nordic and Cornell are the most commonly used scales for this purpose $(10,11)$. Cornell questionnaire is used to determine the pain level among the office workers as a response to relaches and ergonomic changes. Cornell questionnaire, which has been shown to be a valid and reliable tool to measure the pain level caused by MDS, can be especially used for this purpose (12).

In the current study, it is aimed to determine whether there is a difference between MSD of people before and during the COVID-19 pandemic and to reveal the factors affecting this by using Cornell questionnaire due to the psycho-social effects and inactivity caused by COVID. 
Sengul, H., Bulut, A., \& Adalan, M, A. (2020). Investigation of the change of lockdowns applied due to COVID-19 pandemic on musculoskeletal discomfort. Journal of Human Sciences, 17(4), 974-985. doi:10.14687/jhs.v17i4.6060

\subsection{Type of the Study}

\section{Material and Method}

This study was carried out in descriptive design.

\subsection{Hypotheses}

$\mathbf{H}_{1}$ : There is a statistically significant difference between the mean frequency of musculoskeletal discomforts in any region of the body before and after COVID-19.

$\mathbf{H}_{2}$ : There is a statistically significant difference between the mean frequency of the pain level due to the musculoskeletal discomforts in any region of the body before and after COVID-19.

\subsection{Sample Group}

The sample group of the study consisted of a total of 1138 people including 650 male and 488 female, who were aged between 12 and 78 years, who were living in different cities in Turkey, and who agreed to participate in the study.

\subsection{Data Collection Tools}

In the study, "Personal Information Form" and Turkish "Cornell Musculoskeletal Discomfort Questionnaire (T-CMDQ)" were used as the data collection tools.

\subsubsection{Socio-Demographic Information Form}

In the study, the personal information form prepared by the researcher consists of the variables as gender, age, educational status of the participants, the nature of the house where they lived, the status of lockdown, status of working from home due to COVID-19 (Table 1), playing active sports-exercise before and during COVID-19, and status of working actively at a job before and during COVID-19 (Table 2).

\subsubsection{Cornell Musculoskeletal Discomfort Questionnaire (T-CMDQ)}

T-CMDQ is a questionnaire that is developed by Cornell and is primarily based on the Scandinavian Musculoskeletal System Questionnaire (13). In the first section of Likert-type scale, the frequency of pain in the body regions are scored. Similarly, in the second and third sections of the scale, the pail level experienced in the specified body regions and the relation of the pain with work are scored by the users.

Original questionnaire is translated into Turkish by Erdinç et al. and the validity and reliability of the questionnaire is tested (14). T-CMDQ is based on the score calculation system and the total discomfort score of different body regions is found by multiplying the scores of frequency, level, and the impact of the discomfort on work (Degree of Affection $=$ Frequency of Pain $\mathrm{x}$ Pain Level x Relation of Pain with Work) and the areas with the highest percentage score compared to the total score of all the body regions evaluated in the questionnaire is used to identify the body regions having the most serious problems.

In the study, the section about the pain related to work was excluded from the questionnaire due to the transition to homeworking system and the lockdown because of the COVID-19 pandemic. It was decided to evaluate the discomfort due to inactivity in different body regions related to the decrease in daily exercise, sports, or routine activities of the participants and the pain level caused by discomfort before and during the pandemic. In the original scale, the body regions were evaluated totally as 20 different body regions due to the separation of 12 different body regions and 8 regions that are separated as left and right. In the current study, since 8 regions of the body were not evaluated as right-left but one-way, the regions of the body that may cause discomfort were evaluated over 12 different body regions in total and the total mean scores were obtained. Questions about musculoskeletal comfort were prepared for participants in two parts. First, they were asked to retrospectively consider the comfort of the musculoskeletal system prior to the COVID-19 pandemic 

pandemic on musculoskeletal discomfort. Journal of Human Sciences, 17(4), 974-985. doi:10.14687/jhs.v17i4.6060

and respond. In the second part, they were also asked about their current musculoskeletal comfort due to the curfew restriction imposed due to the COVID-19 pandemic.

At first, the participants were asked to assess the frequency of total discomfort of different body regions on a 5-point Likert scale $($ None $=1,1-2$ times a week $=2,3-4$ times a week $=3$, Once a day $=4$, many times every day $=5$ ). Although the lowest score that can be obtained from this section is " 12 ", the highest score is " 60 ". Secondly, it was asked to the participants to indicate the pain level regarding the discomfort at different body regions on a 3-Likert scale (Mild=1, Moderate $=2$, Very severe=3). The lowest score that can be obtained from the pain level section is " 12 ", while the highest score is " 36 ".

In the study, Cronbach alpha value of the total score of Turkish version of Cornell, TCMDQ, was found as 0.92 . It explains $91.9 \%$ of the total variance.

\subsection{Data Collection Method}

The test method conducted in computer environment applied to 1138 participants, who agreed to participate in the research with their own consent, was used as the data collection method in the study. According to the results of a meta-analysis carried out in Turkey, there was no statistically significant difference between the paper and pencil form the student performances shown in the tests applied in a computer environment (15). The form of the scale applied to the participants in the study was sent to the participants in computer environment. After the sufficient sample size was reached in the study, the application was terminated.

\subsection{Ethical Direction of the Research}

In the study, decision of the ethics committee was taken for the non-interventional practices from the ethics committee of Sabahattin Zaim University (Dated 2020 with no. 06).

\subsection{Data Analysis}

Data analysis was performed by using SPSS (Statistical Package for Social Sciences) for Windows 24 program. According to the answers of a total of 1138 participants, who accepted to participate in the research and were living at different cities in Turkey, the distribution of the questions in the personal information form was determined by the frequency analysis and descriptive statistics were conducted.

In the study, parametric test statistics were used to compare the data. Paired Sample t-Test statistics was used for the comparison of the total mean scores obtained from the scale. Significance level was accepted as $\mathrm{p}<0.001$.

\section{Results}

Table 1 shows socio-demographic characteristics of the participants. The average age was $35.69 \pm 11.6$ and the genders of the participants were male with $57.1 \%$ and female with $42.9 \%$. It was determined that the education level of the participants was "undergraduate" with the highest rate of $48.9 \%$, the quality of the house was the apartment flat of $61.2 \%$, and the application of lockdown was $92.8 \%$. 
Sengul, H., Bulut, A., \& Adalan, M, A. (2020). Investigation of the change of lockdowns applied due to COVID-19 pandemic on musculoskeletal discomfort. Journal of Human Sciences, 17(4), 974-985. doi:10.14687/jhs.v17i4.6060

Table 1. Socio-demographic characteristics of the participants $(n=1138)$

\begin{tabular}{lcc}
\hline Variables & $\mathbf{n}$ & $\%$ \\
Gender & 488 & 42.9 \\
Female & 650 & 57.1 \\
Male & 19 & \\
Age: (Ave=35.69; \pm 11.6$)$ & 274 & 1.7 \\
Between 12 and 18 years old & 711 & 24.1 \\
Between 19 and 25 years old & 134 & 62.5 \\
Between 26 and 50 years old & & 11.8 \\
51-year-old and over & 54 & \\
Educational status & 161 & 4.7 \\
Primary education & 115 & 14.1 \\
High School & 557 & 10.1 \\
Associate degree & 251 & 48.9 \\
Undergraduate & & 22.1 \\
Postgraduate & 148 & 13.0 \\
Quality of the house & 696 & 61.2 \\
Detached house & 129 & 11.3 \\
Flat & 165 & 14.5 \\
Site with no social opportunities & & \\
Site with social opportunities & & \\
\hline
\end{tabular}

Table 2 shows characteristics of the business life and daily activity routines of the participants regarding the COVID-19 pandemic. It was reported that the status of working at home due to COVID-19 was $60.3 \%$, status of performing active sports-exercise before and before and during COVID-19 decreased from $42.6 \%$ to $25.9 \%$, and the status of actively working at a job decreased from $72.5 \%$ to $49.6 \%$ before and during COVID-19.

Table 2. Characteristics of status of the participants to be affected by COVID-19 pandemic

\begin{tabular}{lcc} 
& $(\mathbf{n}=1138)$ & $\%$ \\
\hline $\begin{array}{l}\text { Variables } \\
\text { Status of Lockdown }\end{array}$ & $\mathbf{n}$ & 7.2 \\
$\begin{array}{l}\text { No lockdown } \\
\text { Lockdown }\end{array}$ & 82 & 92.8 \\
Working at home due to COVID- & 1.056 & \\
$\mathbf{1 9}$ & & 60.3 \\
No & 686 & 39.7 \\
Yes & 452 & \\
Actively working at a job before & & 27.5 \\
COVID-19 & 313 & 72.5 \\
No & 825 & \\
Yes & & \\
Performing active sports-exercise & & 57.4 \\
before COVID-19 & 653 & 42.6 \\
No & 485 & \\
Yes & & 50.4 \\
Actively working at a job during & 573 & 49.6 \\
COVID-19 & 565 & \\
No & & 74.1 \\
Yes & & 25.9 \\
\hline Performing active sports-exercise & 843 & \\
during COVID-19 & 295 & \\
Yes & &
\end{tabular}

Table 3 shows the distribution of the daily activities of the participants before and during COVID-19. Accordingly, the period of the participants spent in sleep increased from 7.23 hours 

pandemic on musculoskeletal discomfort. Journal of Human Sciences, 17(4), 974-985. doi:10.14687/jhs.v17i4.6060

to 7.98 hours, sitting period increased from 5.69 hours to 8.74 hours, period elapsed before computer increased from 3.37 hours to 4.56 hours, and period elapsed by using mobile phones increased from 3.41 hours to 5.49 hours before and during COVID-19.

Table 3. Distribution of daily activities of the participants before and during COVID-19 (n=1138)

\begin{tabular}{|c|c|c|c|c|c|c|c|c|c|c|c|c|c|c|c|c|}
\hline & \multicolumn{8}{|c|}{ Before COVID-19 } & \multicolumn{8}{|c|}{ During COVID-19 } \\
\hline & \multicolumn{2}{|c|}{$\begin{array}{c}\text { Sleep } \\
\text { duration }\end{array}$} & \multicolumn{2}{|c|}{$\begin{array}{l}\text { Sitting } \\
\text { duration }\end{array}$} & \multicolumn{2}{|c|}{$\begin{array}{l}\text { Period for } \\
\text { using } \\
\text { computer }\end{array}$} & \multicolumn{2}{|c|}{$\begin{array}{c}\text { Period for } \\
\text { using } \\
\text { mobile } \\
\text { phones }\end{array}$} & \multicolumn{2}{|c|}{$\begin{array}{c}\text { Sleep } \\
\text { duration }\end{array}$} & \multicolumn{2}{|c|}{$\begin{array}{c}\text { Sitting } \\
\text { duration }\end{array}$} & \multicolumn{2}{|c|}{$\begin{array}{c}\text { Period for } \\
\text { using } \\
\text { computer }\end{array}$} & \multicolumn{2}{|c|}{$\begin{array}{c}\text { Period for } \\
\text { using } \\
\text { mobile } \\
\text { phones }\end{array}$} \\
\hline Mean & \multicolumn{2}{|c|}{7.23} & \multicolumn{2}{|c|}{5.69} & \multicolumn{2}{|c|}{3.37} & \multicolumn{2}{|c|}{3.41} & \multicolumn{2}{|c|}{7.98} & \multicolumn{2}{|c|}{8.74} & \multicolumn{2}{|c|}{4.56} & \multicolumn{2}{|c|}{5.49} \\
\hline Sd. & \multicolumn{2}{|c|}{1.12} & \multicolumn{2}{|c|}{3.04} & \multicolumn{2}{|c|}{3.15} & \multicolumn{2}{|c|}{2.82} & \multicolumn{2}{|c|}{1.84} & \multicolumn{2}{|c|}{4.16} & \multicolumn{2}{|c|}{3.79} & \multicolumn{2}{|c|}{3.8} \\
\hline Groups & $\mathrm{n}$ & $\%$ & $\mathrm{n}$ & $\%$ & $\mathrm{n}$ & $\%$ & $\mathrm{n}$ & $\%$ & $\mathrm{n}$ & $\%$ & $\mathrm{n}$ & $\%$ & $\mathrm{n}$ & $\%$ & $\mathrm{n}$ & $\%$ \\
\hline $1-5$ hours & 56 & 4.9 & 652 & 57.3 & 870 & 76.4 & 985 & 86.6 & 86 & 7.6 & 258 & 22.7 & 739 & 64.9 & 701 & 61.6 \\
\hline 6-10 hours & 1.077 & 94.6 & 422 & 37.1 & 249 & 21.9 & 118 & 10.4 & 973 & 85.5 & 592 & 52 & 324 & 28.5 & 351 & 30.8 \\
\hline 11-15 hours & 5 & 0.4 & 52 & 4.6 & 18 & 1.6 & 21 & 1.8 & 78 & 6.9 & 226 & 19.9 & 67 & 5.9 & 54 & 4.7 \\
\hline 16-24 hours & 0 & 0 & 12 & 1.1 & 1 & 0.1 & 14 & 1.2 & 1 & 0.1 & 62 & 5.4 & 8 & 0.7 & 32 & 2.8 \\
\hline
\end{tabular}

Table 4 shows the distribution of the participants regarding the frequency of the feeling pain, aches, and discomfort in the body regions before COVID-19. The first three body regions where total MSD frequency of the participants at all levels before COVID-19 was the highest were determined to be neck at the rate of $76.0 \%(n=865)$, back at the rate of $75.7 \%(n=860)$ and waist at the rate of $73.4 \%(n=835)$.

Table 4. Frequency of MSD of the participants according to the body regions before COVID-19 $(\mathrm{n}=1138)$

\begin{tabular}{|c|c|c|c|c|c|c|c|c|c|c|c|c|}
\hline \multirow[t]{2}{*}{ Frequency } & \multicolumn{2}{|c|}{ None } & \multicolumn{2}{|c|}{$\begin{array}{c}\text { 1-2 times a } \\
\text { week }\end{array}$} & \multicolumn{2}{|c|}{$\begin{array}{l}\text { 3-4 times a } \\
\text { week }\end{array}$} & \multicolumn{2}{|c|}{ Once a day } & \multicolumn{2}{|c|}{$\begin{array}{c}\text { Many times } \\
\text { every day }\end{array}$} & \multicolumn{2}{|c|}{$\begin{array}{c}\text { Total } \\
\text { frequency of } \\
\text { MSD }\end{array}$} \\
\hline & n & $\%$ & $\mathrm{n}$ & $\%$ & $\mathbf{n}$ & $\%$ & $\mathrm{n}$ & $\%$ & $\mathbf{n}$ & $\%$ & $\mathrm{n}$ & $\%$ \\
\hline Neck & 273 & 24.0 & 603 & 53.0 & 180 & 15.8 & 32 & 2.8 & 50 & 4.4 & 865 & 76.0 \\
\hline Shoulders & 332 & 29.2 & 544 & 47.8 & 169 & 14.9 & 42 & 3.7 & 51 & 4.5 & 806 & 70.8 \\
\hline Back & 277 & 24.3 & 530 & 46.6 & 232 & 20.4 & 42 & 3.7 & 57 & 5.0 & 861 & 75.7 \\
\hline Waist & 303 & 26.6 & 546 & 48.0 & 192 & 16.9 & 40 & 3.5 & 57 & 5.0 & 835 & 73.4 \\
\hline $\begin{array}{l}\text { Forearm (between } \\
\text { the elbow and } \\
\text { wrist) }\end{array}$ & 536 & 47.1 & 505 & 44.4 & 63 & 5.5 & 19 & 1.7 & 15 & 1.3 & 602 & 52.9 \\
\hline Wrist & 508 & 44.6 & 514 & 45.2 & 79 & 6.9 & 23 & 2.0 & 14 & 1.2 & 630 & 55.3 \\
\hline Knee & 474 & 41.7 & 496 & 43.6 & 118 & 10.4 & 24 & 2.1 & 26 & 2.3 & 664 & 58.3 \\
\hline $\begin{array}{l}\text { Lower leg (between } \\
\text { the knee and the } \\
\text { foot) }\end{array}$ & 534 & 46.9 & 473 & 41.6 & 91 & 8.0 & 24 & 2.1 & 16 & 1.4 & 604 & 53.1 \\
\hline Feet & 479 & 42.1 & 507 & 44.6 & 102 & 9.0 & 26 & 2.3 & 24 & 2.1 & 659 & 57.9 \\
\hline
\end{tabular}

Table 5 shows the distribution of the participants regarding the frequency of the feeling pain, aches, and discomfort in the body regions during COVID-19. The first three body regions where total MSD frequency of the participants at all levels during COVID-19 was the highest were determined to be neck at the rate of $76.9 \%(n=875)$, back at the rate of $70.6 \%(n=803)$, and waist at the rate of $66.2 \%(n=853)$. 
Sengul, H., Bulut, A., \& Adalan, M, A. (2020). Investigation of the change of lockdowns applied due to COVID-19 pandemic on musculoskeletal discomfort. Journal of Human Sciences, 17(4), 974-985. doi:10.14687/jhs.v17i4.6060

Table 5. Frequency of MSD of the participants according to the body regions during COVID-19 $(\mathrm{n}=1138)$

\begin{tabular}{|c|c|c|c|c|c|c|c|c|c|c|c|c|}
\hline \multirow[t]{2}{*}{ Frequency } & \multicolumn{2}{|c|}{ None } & \multicolumn{2}{|c|}{$\begin{array}{l}\text { 1-2 times a } \\
\text { week }\end{array}$} & \multicolumn{2}{|c|}{$\begin{array}{l}\text { 3-4 times a } \\
\text { week }\end{array}$} & \multicolumn{2}{|c|}{ Once a day } & \multicolumn{2}{|c|}{$\begin{array}{l}\text { Many times } \\
\text { every day }\end{array}$} & \multicolumn{2}{|c|}{$\begin{array}{c}\text { Total } \\
\text { frequency of } \\
\text { MSD }\end{array}$} \\
\hline & $\mathrm{n}$ & $\%$ & $\mathrm{n}$ & $\%$ & $\mathrm{n}$ & $\%$ & $\mathrm{n}$ & $\%$ & $\mathrm{n}$ & $\%$ & $\mathrm{n}$ & $\%$ \\
\hline Neck & 263 & 23.1 & 753 & 66.2 & 72 & 6.3 & 19 & 1.7 & 31 & 2.7 & 875 & 76.9 \\
\hline Shoulders & 393 & 34.5 & 642 & 56.4 & 57 & 5.0 & 14 & 1.2 & 32 & 2.8 & 745 & 65.5 \\
\hline Back & 335 & 29.4 & 682 & 59.9 & 74 & 6.5 & 21 & 1.8 & 26 & 2.3 & 803 & 70.6 \\
\hline $\begin{array}{l}\text { Between the shoulder and } \\
\text { elbow }\end{array}$ & 540 & 47.5 & 539 & 47.4 & 39 & 3.4 & 8 & 0.7 & 12 & 1.1 & 598 & 52.5 \\
\hline Waist & 385 & 33.8 & 632 & 55.5 & 88 & 7.7 & 11 & 1.0 & 22 & 1.9 & 753 & 66.2 \\
\hline $\begin{array}{l}\text { Forearm (between the elbow } \\
\text { and wrist) }\end{array}$ & 604 & 53.1 & 493 & 43.3 & 28 & 2.5 & 9 & 0.8 & 4 & 0.4 & 534 & 46.9 \\
\hline Wrist & 581 & 51.1 & 512 & 45.0 & 32 & 2.8 & 6 & 0.5 & 7 & 0.6 & 557 & 48.9 \\
\hline Fingers & 611 & 53.7 & 491 & 43.1 & 26 & 2.3 & 5 & 0.4 & 5 & 0.4 & 527 & 46.3 \\
\hline Hip & 544 & 47.8 & 529 & 46.5 & 45 & 4.0 & 8 & 0.7 & 12 & 1.1 & 594 & 52.2 \\
\hline $\begin{array}{l}\text { Upper leg (between the hip } \\
\text { and the knee) }\end{array}$ & 570 & 50.1 & 515 & 45.3 & 37 & 3.3 & 9 & 0.8 & 7 & 0.6 & 568 & 49.9 \\
\hline Knee & 529 & 46.5 & 536 & 47.1 & 50 & 4.4 & 9 & 0.8 & 14 & 1.2 & 609 & 53.5 \\
\hline $\begin{array}{l}\text { Lower leg (between the knee } \\
\text { and the foot) }\end{array}$ & 585 & 51.4 & 503 & 44.2 & 32 & 2.8 & 9 & 0.8 & 9 & 0.8 & 553 & 48.6 \\
\hline Feet & 569 & 50.0 & 513 & 45.1 & 35 & 3.1 & 13 & 1.1 & 8 & 0.7 & 569 & 50.0 \\
\hline
\end{tabular}

Table 6 shows the distribution of the pain level felt in the body regions of the participants due to MSD before COVID-19. The first three body regions where total pain level of the participants at all levels before COVID-19 was the highest were determined to be neck at the rate of $76.0 \%(n=865)$, back at the rate of $75.7 \%(n=860)$ and waist at the rate of $73.4 \%(n=835)$.

Table 6. Distribution of the pain level felt in the body regions of the participants due to MSD before COVID-19

\begin{tabular}{|c|c|c|c|c|c|c|c|c|}
\hline \multirow[t]{2}{*}{ Frequency } & \multicolumn{2}{|c|}{ Mild severity } & \multicolumn{2}{|c|}{$\begin{array}{l}\text { Moderate } \\
\text { severity }\end{array}$} & \multicolumn{2}{|c|}{$\begin{array}{l}\text { Extreme } \\
\text { severity }\end{array}$} & \multicolumn{2}{|c|}{$\begin{array}{l}\text { Total of the pain } \\
\text { strength level }\end{array}$} \\
\hline & n & $\%$ & n & $\%$ & $\mathrm{n}$ & $\%$ & n & $\%$ \\
\hline Neck & 554 & 48.7 & 257 & 22.6 & 54 & 4.7 & 865 & 76.0 \\
\hline Shoulders & 268 & 23.6 & 37 & 3.3 & 501 & 44.0 & 806 & 70.8 \\
\hline Back & 505 & 44.4 & 296 & 26.0 & 59 & 5.2 & 860 & 75.6 \\
\hline Between the shoulder and elbow & 536 & 47.1 & 127 & 11.2 & 22 & 1.9 & 685 & 60.2 \\
\hline Waist & 481 & 42.3 & 295 & 25.9 & 59 & 5.2 & 835 & 73.4 \\
\hline Forearm (between the elbow and wrist) & 497 & 43.7 & 97 & 8.5 & 8 & .7 & 602 & 52.9 \\
\hline Wrist & 523 & 46.0 & 93 & 8.2 & 14 & 1.2 & 630 & 55.4 \\
\hline Fingers & 521 & 45.8 & 81 & 7.1 & 12 & 1.1 & 614 & 54.0 \\
\hline Hip & 456 & 40.1 & 174 & 15.3 & 29 & 2.5 & 659 & 57.9 \\
\hline Upper leg (between the hip and the knee) & 436 & 38.3 & 150 & 13.2 & 29 & 2.5 & 615 & 54.0 \\
\hline Knee & 464 & 40.8 & 169 & 14.9 & 31 & 2.7 & 664 & 58.3 \\
\hline Lower leg (between the knee and the foot) & 444 & 39.0 & 137 & 12.0 & 23 & 2.0 & 604 & 53.1 \\
\hline Feet & 496 & 43.6 & 141 & 12.4 & 22 & 1.9 & 659 & 57.9 \\
\hline
\end{tabular}

Table 7 shows the distribution of the pain level felt in the body regions of the participants due to MSD during COVID-19. The first three body regions where total pain level of the participants at all levels during COVID-19 was the highest were determined to be neck at the rate of $76.9 \%(n=875)$, back at the rate of $75.2 \%(n=856)$, and waist at the rate of $72.8 \%(n=828)$. 
Sengul, H., Bulut, A., \& Adalan, M, A. (2020). Investigation of the change of lockdowns applied due to COVID-19 pandemic on musculoskeletal discomfort. Journal of Human Sciences, 17(4), 974-985. doi:10.14687/jhs.v17i4.6060

Table 7. Distribution of the pain level felt in the body regions of the participants due to MSD during COVID-19

\begin{tabular}{|c|c|c|c|c|c|c|c|c|}
\hline \multirow{2}{*}{ Frequency } & \multicolumn{2}{|c|}{ Mild severity } & \multicolumn{2}{|c|}{ Moderate severity } & \multicolumn{2}{|c|}{ Extreme severity } & \multicolumn{2}{|c|}{$\begin{array}{l}\text { Total of the pain } \\
\text { strength level }\end{array}$} \\
\hline & n & $\%$ & $\mathbf{n}$ & $\%$ & n & $\%$ & n & $\%$ \\
\hline Neck & 513 & 45.1 & 276 & 24.3 & 86 & 7.6 & 875 & 76.9 \\
\hline Shoulders & 470 & 41.3 & 280 & 24.6 & 70 & 6.2 & 820 & 72.1 \\
\hline Back & 440 & 38.7 & 327 & 28.7 & 89 & 7.8 & 856 & 75.2 \\
\hline Between the shoulder and elbow & 511 & 44.9 & 168 & 14.8 & 24 & 2.1 & 703 & 61.8 \\
\hline Waist & 427 & 37.5 & 320 & 28.1 & 81 & 7.1 & 828 & 72.8 \\
\hline Forearm (between the elbow and wrist) & 525 & 46.1 & 138 & 12.1 & 17 & 1.5 & 680 & 59.8 \\
\hline Wrist & 525 & 46.1 & 130 & 11.4 & 23 & 2.0 & 678 & 59.6 \\
\hline Fingers & 529 & 46.5 & 116 & 10.2 & 21 & 1.8 & 666 & 58.5 \\
\hline Hip & 441 & 38.8 & 202 & 17.8 & 48 & 4.2 & 691 & 60.7 \\
\hline Upper leg (between the hip and the knee) & 473 & 41.6 & 164 & 14.4 & 35 & 3.1 & 672 & 59.1 \\
\hline Knee & 472 & 41.5 & 192 & 16.9 & 45 & 4.0 & 709 & 62.3 \\
\hline $\begin{array}{l}\text { Lower leg (between the knee and the } \\
\text { foot) }\end{array}$ & 462 & 40.6 & 164 & 14.4 & 39 & 3.4 & 665 & 58.4 \\
\hline Feet & 483 & 42.4 & 162 & 14.2 & 37 & 3.3 & 682 & 59.9 \\
\hline
\end{tabular}

In the study, the comparison of MSD frequency and pain level related to MSD of the participants according to the gender groups before and during COVID-19 were analyzed by the ttest and the results are given in Table 8 . As a result of the independent t-test, a statistically significant difference was found between the total scores of the MSD frequency of the participants before and during COVID-19 and the gender variable $(p<0.001)$. A statistically significant difference was found between the total scores of pain level related to MSD of the participants before and during COVID-19 and the gender variable ( $\mathrm{p}<0.001)$.

When the effect size of MSD before COVID-19 was assessed according to gender, a significant difference having a small effect value (Cohen's $\mathrm{d}=0.036)$ was found between the groups. When the effect size of MSD during COVID-19 was assessed according to gender, a significant difference having a small effect value (Cohen's $d=0.031$ ) was found between the groups.

When the effect size of the pain level related to MSD frequency before COVID-19 was assessed according to gender, a significant difference having a moderate effect value (Cohen's $\mathrm{d}=0.055)$ was found between the groups. A significant difference having a moderate effect value (Cohen's $\mathrm{d}=0.061$ ) was found between the groups when the effect size of the pain level related to MSD frequency during COVID-19 was assessed according to gender.

Table 8. t-test results of the participants according to gender

\begin{tabular}{|c|c|c|c|c|c|c|c|}
\hline Gender & & $\mathbf{N}$ & $x^{-}$ & sd & $\mathbf{t}$ & $\mathrm{p}$ & Cohen's d \\
\hline \multirow{2}{*}{ MSD frequency before COVID-19 } & Female & 488 & 23.8 & 8.1 & \multirow{2}{*}{6.527} & \multirow{2}{*}{$<0.001$} & \multirow{2}{*}{0.036} \\
\hline & Male & 650 & 21.0 & 6.7 & & & \\
\hline \multirow{2}{*}{$\begin{array}{l}\text { Pain level related to MSD before } \\
\text { COVID-19 }\end{array}$} & Female & 231 & 17.5 & 4.7 & \multirow{2}{*}{5.408} & \multirow{2}{*}{$<0.001$} & \multirow{2}{*}{0.055} \\
\hline & Male & 269 & 15.3 & 4.3 & & & \\
\hline \multirow{2}{*}{ MSD frequency during COVID-19 } & Female & 488 & 21.4 & 7.2 & \multirow{2}{*}{6.012} & \multirow{2}{*}{$<0.001$} & \multirow{2}{*}{0.031} \\
\hline & Male & 650 & 19.0 & 6.0 & & & \\
\hline \multirow{2}{*}{$\begin{array}{l}\text { Pain level related to MSD during } \\
\text { COVID-19 }\end{array}$} & Female & 266 & 18.3 & 5.3 & \multirow{2}{*}{6.075} & \multirow{2}{*}{$<0.001$} & \multirow{2}{*}{0.061} \\
\hline & Male & 308 & 15.8 & 4.6 & & & \\
\hline
\end{tabular}

In the study, the comparison of MSD frequency and pain level related to MSD of the participants according to the groups with the status of performing sports or exercise before and after COVID-19 were analysed by the t-test and the results are given in Table 9.

As a result of the independent t-test, no statistically significant difference was found between the total scores of the MSD frequency of the participants before COVID-19 and the 
Sengul, H., Bulut, A., \& Adalan, M, A. (2020). Investigation of the change of lockdowns applied due to COVID-19 pandemic on musculoskeletal discomfort. Journal of Human Sciences, 17(4), 974-985. doi:10.14687/jhs.v17i4.6060

variable of playing sports or exercise ( $\mathrm{p}>0.05)$. No statistically significant difference was found between the total scores of pain level related to MSD and the variable of playing sports or exercise of the participants before COVID-19 ( $\mathrm{p}>0.05$ ).

As a result of the independent $\mathrm{t}$-test, a statistically significant difference was found between the total scores of the MSD frequency and the variable of playing sports or exercise of the participants during COVID-19 ( $\mathrm{p}<0.05$ ). A statistically significant difference was found between the total scores of pain level related to MSD and the variable of playing sports or exercise of the participants of the participants during COVID-19 ( $\mathrm{p}<0.05)$.

A significant difference having a small effect value (Cohen's $\mathrm{d}=0.008)$ was found between the groups when the effect size of MSD during COVID-19 was assessed according to the status of playing sports or exercise. When the effect size of the pain level related to MSD frequency during COVID-19 was assessed according to the status of playing sports or exercise, a significant difference having a small effect value (Cohen's $\mathrm{d}=0.009$ ) was found between the groups.

Table 9. T-test results of the participants according to their status of playing sports or exercise

\begin{tabular}{|c|c|c|c|c|c|c|c|}
\hline \multicolumn{2}{|c|}{ Status of playing sports or exercise } & \multirow{2}{*}{$\begin{array}{c}\mathbf{N} \\
653\end{array}$} & \multirow{2}{*}{$\begin{array}{c}x^{-} \\
22.2\end{array}$} & \multirow{2}{*}{$\begin{array}{l}\mathbf{s d} \\
7.6\end{array}$} & \multirow{3}{*}{$\begin{array}{c}\mathbf{t} \\
0.270\end{array}$} & \multirow{3}{*}{$\begin{array}{c}\mathbf{p} \\
0.787\end{array}$} & \multirow{3}{*}{$\begin{array}{c}\text { Cohen's } \\
\text { d }\end{array}$} \\
\hline \multirow{2}{*}{$\begin{array}{l}\text { MSD frequency before } \\
\text { COVID-19 }\end{array}$} & $\begin{array}{l}\text { Not playing sports or } \\
\text { exercise }\end{array}$ & & & & & & \\
\hline & Playing sports or exercise & 485 & 22.1 & 7.2 & & & \\
\hline \multirow{2}{*}{$\begin{array}{l}\text { Pain level related to MSD } \\
\text { before COVID-19 }\end{array}$} & $\begin{array}{l}\text { Not playing sports or } \\
\text { exercise }\end{array}$ & 269 & 16.4 & 4.4 & \multirow[t]{2}{*}{0.618} & \multirow[t]{2}{*}{0.537} & \\
\hline & Playing sports or exercise & 231 & 16.2 & 4.8 & & & \\
\hline \multirow{2}{*}{$\begin{array}{l}\text { MSD frequency during } \\
\text { COVID-19 }\end{array}$} & $\begin{array}{l}\text { Not playing sports or } \\
\text { exercise }\end{array}$ & 843 & 20.4 & 6.7 & \multirow[t]{2}{*}{3.083} & \multirow[t]{2}{*}{$0.002 *$} & \multirow[t]{2}{*}{0.008} \\
\hline & Playing sports or exercise & 295 & 19.0 & 6.2 & & & \\
\hline \multirow{2}{*}{$\begin{array}{l}\text { Pain level related to MSD } \\
\text { during COVID-19 }\end{array}$} & $\begin{array}{l}\text { Not playing sports or } \\
\text { exercise }\end{array}$ & 429 & 17.2 & 5.1 & \multirow[t]{2}{*}{2.243} & \multirow[t]{2}{*}{$0.025 *$} & \multirow[t]{2}{*}{0.009} \\
\hline & Playing sports or exercise & 145 & 16.1 & 5.0 & & & \\
\hline
\end{tabular}

$*_{p}<0.05$

In the study, the mean total scores of the frequency of pain, aches and discomfort in the body regions of the participants before and during COVID-19 are shown in Table 10. It was determined that there was a statistically significant difference between the total mean scores of the participants before COVID-19 and during COVID-19 ( $\mathrm{p}<0.001)$. The frequency of feeling pain, aches and discomfort in the body regions before COVID-19 was found to be higher than during COVID-19. Decrease was observed in feeling pain, aches and discomfort in the body regions and also in the MSD frequency during COVID-19. When the effect size of the difference was examined, it was found that the effect was small (Cohen's $d=0,38$ ).

Table 10. Paired samples t-test for the difference between the scores of the MSD frequency of the participants before COVID-19 and during COVID-19

\begin{tabular}{lccccccc}
\hline & $\mathbf{N}$ & $\boldsymbol{X}$ & $\mathbf{s d}$ & $\mathbf{t}$ & $\mathbf{d f}$ & $\mathbf{p}$ & Cohen's d \\
\hline Before COVID-19 & 1.138 & 22.20 & 7.43 & & & & 0.38 \\
During COVID-19 & 1.138 & 20.05 & 6.60 & & & & \\
\hline
\end{tabular}

In the study, Table 11 shows the mean total scores of pain level according to feeling pain, aches and discomfort in the body regions of the participants before and during COVID-19. There was a statistically significant difference between the total mean scores of the participants regarding 
Sengul, H., Bulut, A., \& Adalan, M, A. (2020). Investigation of the change of lockdowns applied due to COVID-19 pandemic on musculoskeletal discomfort. Journal of Human Sciences, 17(4), 974-985. doi:10.14687/jhs.v17i4.6060

the pain level before COVID-19 and during COVID-19 ( $\mathrm{p}<0.001$ ). Total mean scores of the pain level before COVID-19 were found to be lower than the scores during COVID-19. It was also determined that an increase occurred in the pain level during COVID-19. When the effect size of the difference was examined, it was found that the effect was small (Cohen's $d=0,32)$.

Table 11. Paired samples t-test for the difference between the scores of the pain level related to MSD of the participants before COVID-19 and during COVID-19

\begin{tabular}{lccccccc}
\hline & $\mathbf{N}$ & $\boldsymbol{X}^{-}$ & $\mathbf{s d}$ & $\mathbf{t}$ & $\mathbf{d f}$ & $\mathbf{p}$ & Cohen's d \\
\hline Pain level before COVID-19 & 500 & 16.30 & 4.61 & & & & \\
Pain level during COVID-19 & 574 & 16.91 & 5.09 & & & & 0.32 \\
\hline
\end{tabular}

\section{Discussion and Conclusion}

The impact of COVID-19 on the musculoskeletal system in the population and whether it will cause any new-onset MSD is currently not known. There are various studies that may suggest that there is a relation between MSD and stress and distress (16,17). A statistically significant differences was observed in terms of time elapsed on sports and exercise before and during quarantine. This can be attributed to the restriction of people from going out for sports, the closure of gyms, and the suspension of such activities by people due to the fear of possible risk of contamination. However, it may verify the facts that sports is actually a habit and an attitude, people are complaining about the lack of time and space, they can actually do their sports at home, and that this is a lifestyle. There was a statistically significant increase in the severity level of lumbar pain, neck pain, and back pain during quarantine when compared to the level before quarantine. Despite it is considered that excessive use of mobile phones and computers causes more stress on posture, it would be possible to say that the large majority do not mind considering postural suggestions, especially when using such devices. This situation is shown together with the statistically significant difference results. The results found in the current assessment supports the results of the study of Rimba et al. conducted in 2019 specifying that improper posture was related to MSD (18). At the same time, statistically significant differences in exposure to electronic devices and musculoskeletal outcomes between genders were found study of Woo, 2016 (19).

Other factors causing MSD are insufficient sleep and reduced physical activity. Sleep withdrawal may cause various musculoskeletal system symptoms that could almost not be distinguished from widespread pain, fatigue, and widespread sensitivity (20). A statistically significant difference was found between the sleeping hours and the severity of MSD as reported by the participants, and in parallel to the current study, it was reported by Topping, 2019 that sleep was related to stress (20). In a study of Almojali et al. conducted in 2017, it was shown that sleep affected MSD and in the study of Tantawy, 2017, sleep affected the level. This also supports the results of the current study $(21,22)$. Heavy workloads and excessive working hours increase musculoskeletal disorders. In the Covid 19 pandemic, people working from home may be the reason for a reduction in musculoskeletal disorders overall.

Various factors exceeding the geographic boundaries around the world contribute to high stress levels. Almost everyone is exposed to unmerciful news and conflicting messages about COVID-19 in the media and this causes the emergence of concerns about routine medical care, family life, working life, and economic issues. The social support system, that decreases with increasing stress factors, social distance, isolation, and quarantine, exacerbates the picture. Giving positive messages to society by benefitting from social media to reduce development of MSD, recommending several exercises for people to do at home, and sharing postural information mentioning about the required sitting position while sitting in front of computer and television or 
Sengul, H., Bulut, A., \& Adalan, M, A. (2020). Investigation of the change of lockdowns applied due to COVID-19 pandemic on musculoskeletal discomfort. Journal of Human Sciences, 17(4), 974-985. doi:10.14687/jhs.v17i4.6060

using mobile phone during such severe pandemic periods affecting public health would contribute to reduce severity of MSD.

\section{References}

1. Feuerstein, M., Shaw, W. S., Nicholas, R. A., \& Huang, G. D. (2004). From confounders to suspected risk factors: psychosocial factors and work-related upper extremity disorders. Journal of Electromyography and Kinesiology, 14(1), 171-178. https://doi.org/10.1016/j.jelekin.2003.09.016

2. Gerr, F., Marcus, M., \& Monteilh, C. (2004). Epidemiology of musculoskeletal disorders among computer users: lesson learned from the role of posture and keyboard use. Journal of Electromyography and Kinesiology, 14(1), 25-31. https://doi.org/10.1016/j.jelekin.2003.09.014

3. Blatter, B. M., \& Bongers, P. M. (2002). Duration of computer use and mouse use in relation to musculoskeletal disorders of neck or upper limb. International Journal of Industrial Ergonomics, 30(45), 295-306. https://doi.org/10.1016/S0169-8141(02)00132-44

4. Kim, Y., Chen, H. T., \& Wang, Y. (2016). Living in the smartphone age: Examining the conditional indirect effects of mobile phone use on political participation. Journal of broadcasting \& electronic media, 60(4), 694-713.https://doi.org/10.1080/08838151.2016.1203318

5. Parent-Thirion A, Fernández Macías E, Hurley J, Vermeylen G. (2007). Fourth European working conditions survey, European foundation for the improvement of living and working conditions. Luxembourg: Office for Official Publications of the European Communities, pp.3761.

6. Pei, H., Yu, S., Babski-Reeves, K., Chu, J., Qu, M., Tian, B., \& Li, W. (2017). Quantification of lower extremity physical exposures in various combinations of sit/stand time duration associated with sit-stand workstation. Medycyna Pracy, 68(3), 315-327.

7. Esmaeilzadeh, S., Ozcan, E., \& Capan, N. (2014). Effects of ergonomic intervention on workrelated upper extremity musculoskeletal disorders among computer workers: a randomized controlled trial. International archives of occupational and environmental health, 87(1), 73-83.

8. Oha, K., Viljasoo, V., \& Merisalu, E. (2010). Prevalence of musculoskeletal disorders, assessment of parameters of muscle tone and health status among office workers. Agron Res, 8(1), 192-200.

9. Hoboub1, N., Choobineh, A., Keshavarz1, S., Kamarı, G.F., \& Khalıfe, M. (2016). Investigating the Association of Work-Related Psycho-Social Factors on Neck Discomforts among Office Personal of Shiraz University of Medical Science.

10. Kahraman, T., Genç, A., \& Göz, E. (2016). The Nordic Musculoskeletal Questionnaire: crosscultural adaptation into Turkish assessing its psychometric properties. Disability and rehabilitation, 38(21), 2153-60.

11. Alaca, N., Safran, E. E., Karamanlargil, A. İ., \& Timucin, E. (2019). Translation and cross-cultural adaptation of the extended version of the Nordic musculoskeletal questionnaire into Turkish. Journal of Musculoskeletal \& Neuronal Interactions, 19(4), 472.

12. Osama, M., Jan, M. B. A., \& Darain, H. (2015). A randomized controlled trial comparing the effects of rest breaks and exercise breaks in reducing musculoskeletal discomfort. Annals of Allied Health Sciences, 1(2), 30-34.

13. Cornell University Ergonomics Web http://www.ergo.human.cornell.edu/cuergoguide.html. Erişim Tarihi; 07/08/2020.

14. Erdinc, O., Hot, K., \& Ozkaya, M. (2011). Turkish version of the Cornell Musculoskeletal Discomfort Questionnaire: cross-cultural adaptation and validation. Work, 39(3), 251-260. https://doi.org/10.3233/WOR-2011-1173

15. Aybek, E. C., Şahin, D. B., Eriş, H. M., Şimşek, A. S., \& Köse, M. (2014). Kağıt-kalem ve bilgisayar formunda uygulanan testlerde öğrenci başarısının karşılaştırıldığ çalışmaların metaanalizi. Asian Journal of Instruction, 2(2), 18. 

pandemic on musculoskeletal discomfort. Journal of Human Sciences, 17(4), 974-985. doi:10.14687/jhs.v17i4.6060

16. Palliser, C. R., Firth, H. M., Feyer, A. M., \& Paulin, S. M. (2005). Musculoskeletal discomfort and work-related stress in New Zealand dentists. Work \& Stress, 19(4), 351-359.

17. Scuffham, A. M., Legg, S. J., Firth, E. C., \& Stevenson, M. A. (2010). Prevalence and risk factors associated with musculoskeletal discomfort in New Zealand veterinarians. Applied ergonomics, 41(3), 444-453.

18. Rimba, J. T., Naiem, F., \& Rahim, M. R. (2019). Relationship between Work Posture and Musculoskeletal Disorders (Msds) at Processing Workers in PtToarco Jaya, Rantepao City year 2017. Indian Journal of Public Health Research \& Development, 10(7), 1025-1029.

19. Woo, E. H., White, P., \& Lai, C. W. (2016). Musculoskeletal impact of the use of various types of electronic devices on university students in Hong Kong: An evaluation by means of selfreported questionnaire. Manual therapy, 26, 47-53.

20. Moldofsky H, Scarisbrick P. (1976). Induction of neurasthenic musculoskeletal pain syndrome by selective sleep stage deprivation. Psychosomatic Med, 38:35-44.

21. Almojali, A. I., Almalki, S. A., Alothman, A. S., Masuadi, E. M., \& Alaqeel, M. K. (2017). The prevalence and association of stress with sleep quality among medical students. Journal of epidemiology and global health, 7(3), 169-174.

22. Tantawy, S. A., Rahman, A. A., \& Ameer, M. A. (2017). The relationship between the development of musculoskeletal disorders, body mass index, and academic stress in Bahraini University students. The Korean journal of pain, 30(2), 126. 